\title{
An Update on the Molecular Pathology of Metaplastic Breast Cancer
}

This article was published in the following Dove Press journal:

Breast Cancer: Targets and Therapy

\author{
Amy E McCart Reed (D) \\ Emarene M Kalaw' \\ Sunil R Lakhani $\mathbb{D}^{1,2}$ \\ 'UQ Centre for Clinical Research, The \\ University of Queensland, Brisbane, \\ Queensland, Australia; ${ }^{2}$ Pathology \\ Queensland, Brisbane, Queensland, \\ Australia
}

\begin{abstract}
Metaplastic breast cancer $(\mathrm{MpBC})$ is a fascinating morphologic sub-type of breast cancer, characterised by intra-tumoural heterogeneity. By definition, these tumors show regions of metaplasia that can present as spindle, squamous, chondroid or even osseous differentiation. $\mathrm{MpBC}$ are typically triple-negative, and are therefore not targetable with hormone therapy or anti-HER2 therapies, leaving only chemotherapeutics for management $\mathrm{MpBC}$ are known for their aggressive course and poor response to chemotherapy. We review herein the pathology and molecular landscape of $\mathrm{MpBC}$ and discuss opportunities for targetted therapies as well as immunotherapies.
\end{abstract}

Keywords: metaplastic, triple-negative breast cancer, precision oncology

\section{Introduction}

Metaplastic breast cancer $(\mathrm{MpBC})$ is a unique histologic subtype of breast cancer, defined by characteristic intra-tumoural heterogeneity. Although rare, $\mathrm{MpBC}$ accounts for significant morbidity and mortality, and has a poor prognosis. $\mathrm{MpBC}$ tend not to respond well to systemic chemotherapies, and together with emerging data on the genomic landscape of $\mathrm{MpBC}$, there is scope for applying precision oncology in the management strategies of $\mathrm{MpBC}$. We focus herein on the molecular pathology of $\mathrm{MpBC}$ and the current status and potential of targeted therapies to manage MpBC.

\section{MpBC Pathology and Presentation}

The clinical features of $\mathrm{MpBC}$ are similar to other high-grade cancers of no special type (NST), however, they often present at a more advanced stage. They tend to be large in size, with dimensions ranging from 1.2 to $>10 \mathrm{~cm}$ and often present as a palpable breast mass, with ill-defined borders on mammography, ultrasonography, and magnetic resonance imaging. MpBC represents $0.2-1 \%$ of all breast cancers the rates vary due to the differing definitions and classification systems used over time.

$\mathrm{MpBC}$ do not have any distinctive macroscopic features, with the tumor varying from well-circumscribed to having an irregular border. Microscopically, they comprise a heterogenous group with differing outcomes. In the absence of sufficient molecular and outcome data, the current WHO Classification of Tumours of the Breast ${ }^{1,2}$ has maintained a descriptive morphological classification system, based on the type of the metaplastic elements present. MpBC are classified monophasic (when there is only one metaplastic component) or biphasic (with two or more metaplastic components
Correspondence: Sunil R Lakhani

Emails.lakhani@uq.edu.au
Breast Cancer: Targets and Therapy 2021:13 161-170 
such as squamous and spindle, or mixed metaplastic and non-metaplastic components - such as spindle and invasive carcinoma NST). Further, MpBC can also be classified into epithelial-only carcinomas (with low-grade adenosquamous carcinoma or pure squamous cell carcinoma), pure (monophasic) sarcomatoid (spindle cell or matrix-producing) carcinomas, and biphasic epithelial and sarcomatoid carcinomas.

\section{Current Histopathological Classification}

The current WHO classification includes (i) adenosquamous carcinoma - mostly low grade but can be high grade rarely and (ii) pure squamous cell carcinomas (iii) pure spindle cell carcinoma (iv) fibromatosis-like metaplastic carcinoma, (iv) metaplastic carcinoma with mesenchymal differentiation that includes chondroid (myxoid/cartilaginous), osseous (bone), rhabdomyoid (muscle) and neuroglial, and (v) mixed metaplastic carcinoma - where the mix may be multiple metaplastic elements or a mixture of epithelial and mesenchymal elements. Examples of the heterologous elements are shown in Figure 1. The detailed morphology of the subtypes is beyond the scope of this review and the reader is directed to the WHO Tumour Classification of the Breast 5th Ed (2019). ${ }^{2}$
$\mathrm{MpBC}$ are typically, though not invariably triplenegative (TN), lacking expression of estrogen and progesterone receptors (ER/PR), and HER2. Analysis of the SEER data showed that HER2 positive MpBC had an improved overall survival compared to $\mathrm{TN}$, and other $\mathrm{MpBC}$ including $\mathrm{ER}+/ \mathrm{PR}+/ \mathrm{HER} 2$-cases, which accounted for $20 \%$ of the cohort. $^{3}$ Conversely, HER2-positive metaplastic squamous cell carcinomas were recently demonstrated to have a poorer prognosis than the $\mathrm{TN}$ metaplastic squamous variants. ${ }^{4}$ MpBC fit into the claudin-low and/or basal breast cancer intrinsic subtypes, 5,6 although whether or not claudin low represents an intrinsic subtype or phenotype has recently come into question. ${ }^{7}$ A recent large meta-analysis reported that approximately three quarters of all $\mathrm{MpBC}$ stain positively for pan-cytokeratin biomarkers (AE1/3, MNF116) and basal cytokeratin biomarkers (34ßE12, CK5/6, CK14 and CK17). GATA3, a common diagnostic marker used to identify tumours of breast origin, is expressed by only $21 \%$ of $\mathrm{MpBC}$, while a novel breast marker, TRPS1, was shown to be highly expressed in $86 \%$ of $\mathrm{MpBC}$, as well as nonmetaplastic TNBC and BC more broadly. ${ }^{8}$ Frequent expression of p63 was also noted, as was an absence of staining for CD34. ${ }^{9}$ Those cases lacking cytokeratin expression were studied in more detail, and determined to be carcinomatous rather than true primary sarcomas in most cases, further evidencing the inter-tumor heterogeneity of breast cancer broadly, and $\mathrm{MpBC}$ specifically. ${ }^{10}$ Indeed, a pure sarcoma
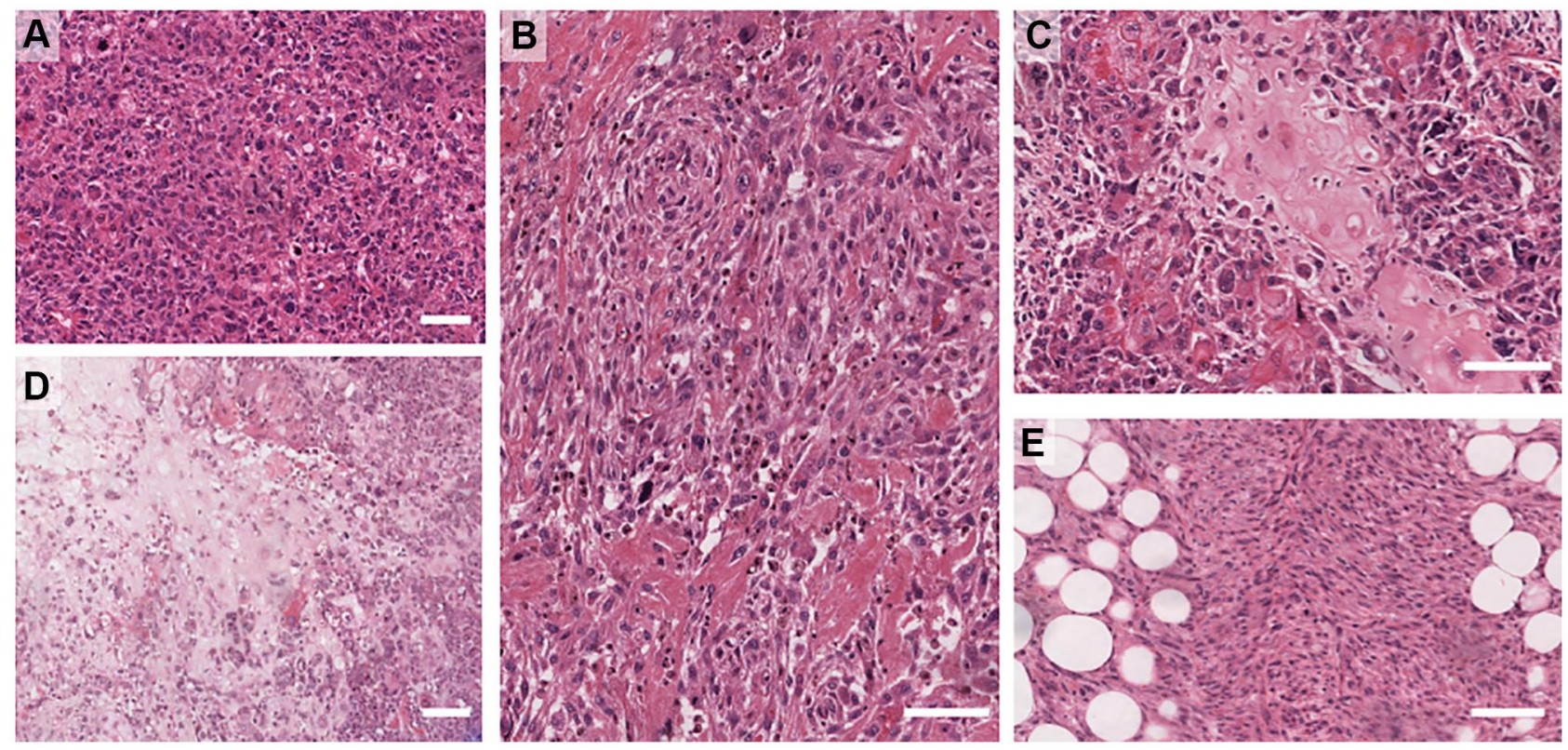

Figure I Examples of Metaplastic breast cancer morphologies. (A) High-grade, pleomorphic de-differentiated carcinoma (IBC-NST). (B) High-grade carcinoma with focal squamous differentiation. (C) Osteoid differentiation. (D) Chondroid differentiation. (E) Spindle differentiation. Scale bar is $100 \mu \mathrm{m}$. 
of the breast is rare and is a diagnosis of exclusion, requiring extensive sampling; negative stains for p63 and a range of cytokeratins; and, a morphological examination for any evidence of epithelial differentiation.

For the adenosquamous and fibromatosis-like variants of $\mathrm{MpBC}$, the grade is implicitly low, and prognostic outcome is better than for the majority of $\mathrm{MpBC}$ which are typically classified as high grade (grade 3) tumors. Although high histologic grading is a relatively consistent finding, its prognostic value is still uncertain. ${ }^{11}$ A subset of $\mathrm{MpBC}$ tumors with extreme, bizarre cytologic pleomorphisms has been reported, ${ }^{11}$ with a noted enrichment in the spindle phenotype.

With respect to the TNM classification system of cancer stage, $\mathrm{MpBC}$ present with a larger tumor size (TNM), with reports indicating that $\sim 60 \%$ of $\mathrm{MpBC}$ have tumors between 2 and $5 \mathrm{~cm}\left(\mathrm{~T} 2 ;^{12}\right)$. As for triple-negative breast cancers more broadly, lymph node (LN; the $\mathrm{N}$ of TNM) positivity is not a prominent feature, with LN metastasis documented in about $24 \%$ of patients. Distant metastasis (TNM) occurs with or without LN spread in MpBC, and spread to the lungs and brain has been reported. ${ }^{13}$

\section{MpBC - A Stem-Like Cancer with Treatment Implications}

The innate plasticity of $\mathrm{MpBC}$ has led to suggestions that it is a stem-cell like breast cancer, and a wealth of data show that $\mathrm{MpBC}$ express classic stem cell markers. It is presently considered that there exist three categories of breast cancer stem cell (CSC): an ALDH+ epithelial-like CSC; CD44+/CD24- mesenchymal-like CSCs; and, a hybrid epithelial/mesenchymal-like $\mathrm{ALDH}+/ \mathrm{CD} 44+/ \mathrm{CD} 24-\left(\right.$ reviewed in detail in $^{14}$ ). The work of Zhang et $\mathrm{al}^{15}$ demonstrated the increased expression of classic stem cell markers ALDH1 and CD44/CD24 ratios in a series of MpBC, much like the above-noted hybrid CSC state, and also expression of characteristic epithelial to mesenchymal transition (EMT) markers (increased ZEB1 and loss of E-cadherin). This expression of stem-like markers was also supported by Gerhard et al, ${ }^{16}$ with most of their series showing positivity for CD44 and loss of CD24, as well as an enrichment for vimentin and loss of the claudins and E-cadherin. Given that cancer stem cells have well-documented chemoresistance, ${ }^{17}$ it is unsurprising that $\mathrm{MpBC}$, with their enrichment of both stemlike markers and the hallmarks of EMT, ${ }^{5,18}$ also respond poorly to chemotherapeutics. Notably, MpBC have a high frequency of PIK3CA mutations (see below) and these mutations correlate with poor response to neoadjuvant chemotherapy in breast cancer subtypes broadly, ${ }^{19}$ and this holds true in the metastatic setting. ${ }^{20}$ Drugs targeting the PI3K/AKT axis are emerging in the clinic, may be appropriate for $\mathrm{MpBC}$, and are discussed further below.

\section{MpBC Molecular Landscape}

As shown in Table 1, the research community has yet to robustly elucidate a molecular landscape for $\mathrm{MpBC}$, most likely due to the extensive sample heterogeneity. There is limited concordance between studies on the mutations present, however this is likely influenced by the sequencing platform (exome vs panel), and also the subtype composition of the cohorts.

PI-3 Kinase and Ras signaling pathway mutations have been shown to be early events in $\mathrm{MpBC}$ pathogenesis. ${ }^{21}$ Mutation frequencies reported for $\mathrm{MpBC}$ range from $26 \%$ $75 \%$ for TP53, and $23 \%-70 \%$ for PIK3CA (Table 1) and this is supported by a recent meta-analysis of 14 studies encompassing 539 cases. ${ }^{22}$ Other than TP53 and PIK3CA, the most frequently identified mutations across multiple cohorts occur in PTEN, NF1, HRAS, PIK3R1. Emerging data support that the various morphologic elements feature subtly different mutation profiles, with for example, a lack of PIK3CA mutations found in those $\mathrm{MpBC}$ with chondroid differentiation. ${ }^{23}$ Chondroid tumors were also shown to lack mutations in TERT promoters. ${ }^{21}$ TERT promoter mutations were enriched in the spindle and squamous type tumors, while TP53 mutations were less likely to be in spindled tumors than other MpBC types. ${ }^{21}$ An increase in mutations in Wnt pathway genes has been reported for MpBCs, ${ }^{23}$ with WISP3/CCN6 mutations more frequently seen in the epithelial components, and 3/7 CTNNB1 mutations present only in the spindle compartment of the tumor. $^{24}$

In spite of the private mutations in the different morphological components as noted above, evidence supports that the different histologies have a shared origin, and following a detailed exome sequencing study, Avigdor et al postulated that methylation and/or non-coding changes may also regulate the phenotypic differentiation. ${ }^{25}$ To clarify the outstanding elements of the genomic landscape of $\mathrm{MpBC}$, a concerted effort must be made to standardize sequencing approaches on an adequately powered cohort of well-annotated $\mathrm{MpBC}$. 
Table I Genetic Alterations Identified Across MpBC Cohorts and Morphologies

\begin{tabular}{|c|c|c|c|c|c|c|c|c|c|c|c|c|c|}
\hline \multirow[t]{2}{*}{ Ref } & \multirow{2}{*}{$\begin{array}{l}\text { Cohort } \\
\text { (n) }\end{array}$} & \multicolumn{12}{|c|}{ Morphologies } \\
\hline & & Sqam & Spin & Chon & Oss & $\begin{array}{l}\text { Spin/ } \\
\text { Squam }\end{array}$ & $\begin{array}{l}\text { Spin/ } \\
\text { Mes }\end{array}$ & $\begin{array}{l}\text { Spin/ } \\
\text { Chon }\end{array}$ & Mes & Myo & Angio & mixed & LGASC \\
\hline $\begin{array}{l}\text { Afkhami et al } \\
2019^{49}\end{array}$ & 19 & 8 & 6 & & & 3 & 2 & & 2 & & & & 10 \\
\hline Bataillon et $\mathrm{al}^{50}$ & 10 & & & & & & & & & & & & \\
\hline $\begin{array}{l}\text { Beca et al } \\
2020^{51}\end{array}$ & 3 & & & & 3 & & & & & & & & \\
\hline $\begin{array}{l}\text { Edenfield et al } \\
2017^{52}\end{array}$ & 25 & 2 & 5 & 18 & & & & & & & & & \\
\hline $\begin{array}{l}\text { Hayes et al } \\
2008^{24}\end{array}$ & 36 & 16 & 12 & 6 & 2 & & & & & & & & \\
\hline $\begin{array}{l}\text { Joneja et al } \\
2017^{53}\end{array}$ & 57 & 18 & 20 & 16 & & & & & & 5 & 1 & 12 & \\
\hline $\begin{array}{l}\text { Krings et al } \\
2018^{21}\end{array}$ & 28 & 5 & 5 & 10 & & 5 & & & & & & 3 & \\
\hline $\begin{array}{l}\text { McCart Reed } \\
2019^{11}\end{array}$ & 30 & 10 & 3 & & & & & & I & & & 16 & \\
\hline $\mathrm{Ng}$ et al $2017^{23}$ & 35 & 9 & 10 & 16 & & & & & & & & & \\
\hline $\begin{array}{l}\text { Ross et al } \\
2015^{54}\end{array}$ & 20 & 9 & 2 & 9 & & & & & & & & & \\
\hline $\begin{array}{l}\text { Tray et al } \\
2018^{55}\end{array}$ & 192 & & & & & & & & & & & & \\
\hline $\begin{array}{l}\text { Vranic et al } \\
2020^{56}\end{array}$ & 23 & & 23 & & & & & & & & & & \\
\hline $\begin{array}{l}\text { Zhai et al } \\
2019^{57}\end{array}$ & 18 & 4 & 9 & 2 & I & 3 & & 2 & & & & & \\
\hline $\begin{array}{l}\text { Dave et al } \\
2017^{58}\end{array}$ & 40 & & & & & & & & & & & & \\
\hline
\end{tabular}

Abbreviations: N/A, not available; NS, not specified; angio, angiosarcomatous; chon, chondroid; LGASC, low grade adenosquamous carcinoma; mes, mesenchymal; myo, myoepithelial; oss, osseous; spin, spindle; squam, squamous.

Uterine carcinosarcoma (UCS) are considered the metaplastic cancers of the gynaecological tract, and a recent study performed a comparative analysis of 57 UCS with $35 \mathrm{MpBC} .{ }^{26}$ Genetic differences unique to the UCS were reported, with a significant enrichment for mutations in FBXW7 and PPP2R1A, and HER2 amplifications, while shared genomic features included alterations in TP53, PIK3CA, PTEN and EMT-related Wnt and Notch signalling components. Interestingly, unlike the UCS, almost half of the profiled MpBC had a dominant homologous recombination deficiency (HRD; signature 3) signature, and these same cases showed other features of a HRD including large scale transitions, and allelic imbalance extending to the telomeres.

\section{Precision Oncology for MpBC}

In the absence of indications for hormone and anti-HER2 therapies, and given their typically large size at presentation, $\mathrm{MpBC}$ are managed with chemotherapeutics in addition to surgery (with/without radiation). However, early 


\begin{tabular}{|c|c|c|c|c|c|}
\hline NS & Platform & $\begin{array}{l}\text { Hypothesis or } \\
\text { Discovery? }\end{array}$ & $\begin{array}{l}\text { TP53 } \\
(n, \%)\end{array}$ & $\begin{array}{l}\text { PIK3CA } \\
(\mathrm{n}, \%)\end{array}$ & Other alterations in at least 2 cases (n, \%) \\
\hline & Onco48 Ion AmpliSeq & $\mathrm{H}$ & $\begin{array}{l}13 / 19 \\
68\end{array}$ & $8 / 19,42$ & $\operatorname{PTEN}(3 / 19,16)$ \\
\hline & $\begin{array}{l}\text { Ion Ampliseq Cancer } \\
\text { Hotspot panel v2 }\end{array}$ & $\mathrm{H}$ & $0 / 10,0$ & $7 / 10,70$ & \\
\hline & $\begin{array}{l}\text { Agilent SureSelect Human All } \\
\text { Exon v4 }\end{array}$ & $\mathrm{D}$ & $3 / 3,100$ & $1 / 3,33.3$ & OSMR $(2 / 3,67)$ \\
\hline & $\begin{array}{l}\text { lon Ampliseq Cancer } \\
\text { Hotspot panel v2 }\end{array}$ & $\mathrm{H}$ & $\begin{array}{l}16 / 25 \\
64\end{array}$ & $12 / 25,48$ & $\operatorname{ERBB} 4(9 / 25,36) ;$ FLT3 $(15 / 25,60)$ \\
\hline & Sanger Sequencing & $\mathrm{H}$ & $N / A$ & $\mathrm{~N} / \mathrm{A}$ & $\begin{array}{l}\text { CTNNBI (7/27, 26); WISP3/CCN6 (5/27, I8.5); APC (2/ } \\
27 ; 7)\end{array}$ \\
\hline 3 & $\begin{array}{l}\text { Illumina TruSeq Amplicon } \\
\text { cancer panel }\end{array}$ & $\mathrm{H}$ & $\begin{array}{l}32 / 57 \\
65\end{array}$ & $13 / 57,23$ & $\operatorname{HRAS}(3 / 57,5)$ \\
\hline & Custom hybrid capture & $\mathrm{H}$ & $\begin{array}{l}18 / 28 \\
64\end{array}$ & $9 / 28,32$ & $\begin{array}{l}\text { TERT }(7 / 28,25) ; \text { HRAS }(2 / 28,7) ; \operatorname{KRAS}(2 / 28,7) ; \mathrm{NFI}(2 / \\
28,7)\end{array}$ \\
\hline & $\begin{array}{l}\text { Illumina Nextera Rapid } \\
\text { Capture Exome }\end{array}$ & $\mathrm{D}$ & $\begin{array}{l}21 / 30 \\
70\end{array}$ & $10 / 30,33$ & $\operatorname{PTEN}(7 / 30,23)$, and NFI $(4 / 30,13)$ \\
\hline & $\begin{array}{l}\text { Agilent SureSelect Human All } \\
\text { Exon v4 }\end{array}$ & $\mathrm{D}$ & $\begin{array}{l}24 / 35 \\
69\end{array}$ & $10 / 35,29$ & $\begin{array}{l}\text { PTEN }(4 / 35, \text { II); ARIDIA }(4 / 35, \text { II }), \text { KMT2C }(4 / 35, \text { I I }) \\
\text { PIK3RI }(4 / 35, \text { II) }\end{array}$ \\
\hline & FoundationOne & $\mathrm{H}$ & $\begin{array}{l}15 / 20 \\
75\end{array}$ & $8 / 25,40$ & $\begin{array}{l}\text { CDKN2A/B }(4 / 20,20) \text {; CCND3 }(3 / 20 ; 15), \text { CCNEI }(2 / 20 \text {, } \\
\text { I0); EGFR }(2 / 20,10)\end{array}$ \\
\hline & FoundationOne & $\mathrm{H}$ & $\begin{array}{l}125 / \\
192,65\end{array}$ & $67 / 192,35$ & \\
\hline & $\begin{array}{l}\text { SureSelect XT, } 592 \text { genes, } \\
\text { Agilent }\end{array}$ & $\mathrm{H}$ & $6 / 23,26$ & $10 / 23,43$ & $\operatorname{PTEN}(3 / 23,13) ; \operatorname{NFI}(4 / 19,17) ; \operatorname{HRAS}(4 / 23,17)$ \\
\hline & $\begin{array}{l}\text { Ion Ampliseq Cancer } \\
\text { Hotspot panel v2 }\end{array}$ & $\mathrm{H}$ & $\begin{array}{l}10 / 18 \\
56\end{array}$ & $7 / 18,39$ & PTEN $(3 / 18,17)$ \\
\hline 40 & CAST PCR & $\mathrm{H}$ & N/A & $N / A$ & RPL39 $(39 / 40,98)$ \\
\hline
\end{tabular}

studies showed that systemic therapy was less effective in $\mathrm{MpBC}^{12}$ and this data has held true over time and is supported by the overall poor outcomes of $\mathrm{MpBC}$ patients. $^{27}$ In fact, while $90 \%$ of diagnoses of $\mathrm{MpBC}$ are for localized disease, half of these patients will progress to advanced BC over time. ${ }^{28,29}$ Treatment in the neoadjuvant setting appears to afford little advantage, with a $10-17 \%$ pathological complete response rate reported ${ }^{30-33}$ for American studies, while studies in Japan and Turkey reported no complete responders. ${ }^{34,35}$ It is clear that efficacious treatments for $\mathrm{MpBC}$ are an unmet clinical need, and while some clinical trials specifically for $\mathrm{MpBC}$ are being initiated, the potential for novel therapeutic interventions must be capitalized upon.

\section{Genomic Biomarkers and Targeted Therapy for MpBC}

$\mathrm{MpBC}$ are characteristically triple-negative $\mathrm{BC}$, thus eliminating these patients from current tailored therapeutic 
Table 2 Active Trials Open to Metaplastic Breast Cancer Patients

\begin{tabular}{|c|c|c|c|}
\hline \multicolumn{3}{|c|}{ Targeted Therapies } & \multirow{2}{*}{ Phase } \\
\hline ARQule & $\begin{array}{l}\text { ARQ75I (pan-AKT inhibitor) with fulvestrant or paclitaxel in patients with PIK3CA/AKT/PTEN } \\
\text { mutations }\end{array}$ & NCT02761694 & \\
\hline ARTEMIS & $\begin{array}{l}\text { A Robust TNBC Evaluation Framework to Improve Survival- molecular profiling of treatment naïve } \\
\text { tumour while patient undergoes NACT; targeted therapy trials recommended where appropriate }\end{array}$ & NCT02276443 & $\mathrm{lb} / \mathrm{ll}$ \\
\hline L-NMMA & Pan-nitric oxide synthase inhibitor plus docetaxel in advanced or metastatic TNBC patients & NCT02834403 & $\mathrm{lb} / \mathrm{ll}$ \\
\hline \multirow[t]{3}{*}{$\begin{array}{l}\text { Women's } \\
\text { MoonShot }\end{array}$} & $\begin{array}{l}\text { Neoadjuvant Treatment with PaCT (panitumumab (anti-EGFR) carboplatin and paclitaxel) for Patients } \\
\text { With Locally Advanced TNBC }\end{array}$ & NCT02593I75 & II \\
\hline & $\begin{array}{l}\text { Enzalutamide and Paclitaxel Before Surgery in Treating Patients With Stage I-III Androgen Receptor- } \\
\text { Positive TNBC }\end{array}$ & NCT02689427 & Ilb \\
\hline & $\begin{array}{l}\text { Liposomal Doxorubicin, Bevacizumab (anti-VEGF), and Everolimus (mTOR inhibitor) in Patients With } \\
\text { Locally Advanced TNBC With Tumors Predicted Insensitive to Standard Chemotherapy; A Moonshot } \\
\text { Initiative }\end{array}$ & NCT02456857 & II \\
\hline \multicolumn{3}{|c|}{ Immunotherapies } & Phase \\
\hline DART & Dual anti-CTLA4 (nivolumab) and anti-PDI (ipilimumab) blockade & NCT02834013 & II \\
\hline $\begin{array}{l}\text { Morpheus- } \\
\text { TNBC }\end{array}$ & $\begin{array}{l}\text { Multiple Immunotherapy-Based Treatment Combinations in Patients With Metastatic or Inoperable } \\
\text { Locally Advanced TNBC }\end{array}$ & NCT03424005 & $\mathrm{lb} / \mathrm{ll}$ \\
\hline \multirow{2}{*}{$\begin{array}{l}\text { SWOG } \\
\text { SI418 }\end{array}$} & Pembrolizumab (anti-PDI) as adjuvant therapy for TNBC after neoadjuvant therapy & NCT02954874 & III \\
\hline & Pembrolizumab (anti-PDI) plus nab-paclitaxel for TNBC and HR+/HER2- breast cancer & NCT02752685 & II \\
\hline TN First-Line & Neoadjuvant Trial of Nab-Paclitaxel and MPDL3280A, a PDL-I Inhibitor in Patients With TNBC & NCT02530489 & II \\
\hline PAveMenT & Palbociclib and Avelumab in Metastatic AR+ TNBC & NCT0436094I & $\mathrm{lb}$ \\
\hline
\end{tabular}

options of hormone therapy and anti-HER2 therapy. This triple-negativity, does however make them eligible for a multitude of trials currently recruiting, including those assessing benefit of immune checkpoint inhibitors; a nonexhaustive list of open trials is presented in Table 2.

$\mathrm{MpBC}$ show frequent alterations in the PI3K/AKT/ mTOR pathway making them candidates for targeted therapies such as everolimus, temsirolimus, and alpelisib. In a Phase I intervention, a $42 \%$ rate of partial/complete remission was reported for a combination of temsirolimus and bevacizumab (HIF inhibitor) ${ }^{36}$ A $25 \%$ response rate (complete/partial response) was achieved in $\mathrm{MpBC}$ treated with temsirolimus/everolimus in combination with standard chemotherapy and a $21 \%$ objective response rate was also reported for the regimen of doxorubicin, bevacizumab and temsirolimus/everolimus, ${ }^{37}$ however genetic analysis showed that while PI3K pathway alterations were associated with a significant improvement in objective response rate (31\% vs $0 \%)$ they were not associated with an improved clinical benefit rate ( $44 \%$ vs $45 \%$ ). Detailed analysis of this trial data showed an improvement in overall survival for the $\mathrm{MpBC}$ patients, and suggests that $\mathrm{MpBC}$ histology is an indicator for doxorubicin with bevacizumab and everolimus/temsirolimus. ${ }^{38}$ A lone MpBC participant in the BELLE-4 Phase II/III trial responded well to a combined therapy of paclitaxel and the PI3K inhibitor buparlisib ${ }^{39}$ although toxicity was noted, and indeed buparlisib was subsequently discontinued from development, with a significantly higher burden of adverse effects noted for buparlisib than alpelisb in the B-YOND (hormone receptor positive, phase Ib) trial. ${ }^{40}$ Pre-clinical data in $\mathrm{MpBC}$ patient derived xenograft models suggest that a combination of PI3K and MAPK inhibitors may be a potential avenue for therapy in PIK3CA mutated MpBC patients. ${ }^{41}$

CDK4/6 inhibitors (eg, ribociclib, palbociclib, abemaciclib) are now approved as standard of care for advanced, hormone receptor positive breast cancers, however this proliferation check-point may also be a useful target in TNBC, and trials are underway to determine the efficacy of this approach (reviewed $\mathrm{in}^{42}$ ), including in combination with 
immune checkpoint inhibitors (PAveMenT: NCT04360941). A recent case report demonstrated a dramatic but short-term benefit from combined dabrafenib and trametinib in an advanced MpBC patient. ${ }^{43}$ Dabrafenib and trametinib target BRAF and MEK signalling, respectively, and their application in $\mathrm{MpBC}$ has not previously been reported.

Although a pre-clinical study did not support the efficacy of PARP inhibitor olaparib in an MpBC-like mouse model, ${ }^{44}$ given the recent evidence of a dominant HRD signature in almost $50 \%$ of the MpBC profiled, ${ }^{26}$ the suggestion by Tray et $\mathrm{al}^{45}$ that PARP inhibition for MpBC needs further study is certainly warranted. These studies together support further investigations into a range of targeted therapies and highlight their potential value in $\mathrm{MpBC}$.

\section{Targeting the MpBC Immune Microenvironment}

The potential benefit of therapeutic modulation of the immune system in breast cancer is becoming increasingly clear for TNBC, as well as MpBC. A case report of a remarkable, durable response to pembrolizumab (anti-PD -1) in combination with nab-Paclitaxel in advanced, pretreated spindled $\mathrm{MpBC}$ was reported in $2017 .{ }^{46} \mathrm{~A}$ similar combination of durvalumab (anti-PD-L1) and paclitaxel was also shown to provide a sustained, complete response in a second case report of advanced $\mathrm{MpBC}$, this time with squamous features. ${ }^{47}$ In this case, $20 \%$ of tumor cells stained with medium intensity (clone SP142), and there was an absence of staining in the TILS; while in the former case, $100 \%$ of tumor cells stained positively for PD-L1 using the $22 \mathrm{C} 3$ clone. Indeed, there is no standardized definition criteria for PD-L1 staining at this stage, and the characterization of expression of this and other immune checkpoint markers across TNBC and MpBC has only recently emerged. As shown in Table 3, heterogeneity in percentage positivity of PD-L1 in tumor cells is reported across TNBC, with a higher rate of positivity consistently reported for $\mathrm{MpBC}$. $\mathrm{MpBC}$ tumor cells show a range of PD-L1 expression from $17 \%$ to $80 \%$, recording both cytoplasmic and membranous staining, and in the immune cells from $48 \%$ to $69 \%$. Combinations of immune-checkpoint inhibitors are also being evaluated, with the DART (Dual Anti-CTLA-4 and Anti-PD-1 blockade in Rare Tumors, Table 2) trial facilitating an MpBC specific assessment. ${ }^{48}$ Primary endpoint data confirmed clinical activity of ipilimumab combined with nivolumab and resulted in 3 cases of 17 showing a durable response, which

Table 3 PD-LI Expression in Metaplastic Breast Cancer

\begin{tabular}{|c|c|c|c|c|c|}
\hline Ref & Year & Cohort & $\begin{array}{l}\text { PD-LI } \\
\text { Antibody } \\
\text { Clone }\end{array}$ & Staining Criteria & $\begin{array}{l}\% \text { Cases with Positive PD-LI } \\
\text { Expression }\end{array}$ \\
\hline Mittendorf et $\mathrm{al}^{59}$ & 2014 & I20 TNBC & $5 \mathrm{HI}$ & Memb. staining in $>5 \%$ tumor cells & $19 \%$ tum \\
\hline Joneja et $\mathrm{al}^{53}$ & 2016 & $\begin{array}{l}297 \mathrm{TNBC} \\
(75 \mathrm{MpBC})\end{array}$ & $\mathrm{SPI} 42$ & $\begin{array}{l}\text { Tumor with } \geq 2+\text { intensity in } \geq 5 \% \text { of the tumor } \\
\text { cells }\end{array}$ & MpBC $46 \%$ tum; $9 \%$ TNBC tum \\
\hline Beckers et al ${ }^{60}$ & 2016 & $161 \mathrm{TNBC}$ & EIL3N & $\begin{array}{l}\geq 1 \% \text { tum memb. or cyto. and } \geq 1 \% \text { immune cells } \\
\text { in the stromal compartment }\end{array}$ & $\begin{array}{l}64 \% \text { tum memb., } 80 \% \text { cyto. and } 93 \% \\
\text { stromal compartment }\end{array}$ \\
\hline Dogukan et al ${ }^{61}$ & 2019 & $\begin{array}{l}61 \text { TNBC } \\
\text { (incl } 6 \\
\text { МpBC) }\end{array}$ & EIL3N & $\begin{array}{l}\text { Memb. or cyto. staining in } \geq 1 \% \text { tumor cells; } \geq 5 \% \\
\text { staining in peri-tumoral regions }\end{array}$ & $\begin{array}{l}38 \% \text { tumor cell; } 48 \% \text { tumor immune } \\
\text { microenvironment }\end{array}$ \\
\hline Morgan et $\mathrm{a}^{62}$ & 2020 & $\begin{array}{l}\text { I } 46 \text { TNBC } \\
(27 \mathrm{MpBC})\end{array}$ & SP263 & $\begin{array}{l}\text { Memb. staining in } \geq 1 \% \text { of tumor cells; immune } \\
\text { cells }\end{array}$ & $\begin{array}{l}\text { MpBC } 30 \% \text { tum, } 73 \% \text { immune; } \\
\text { TNBC } 10 \% \text { tum, } 59 \% \text { immune }\end{array}$ \\
\hline Afkhani et $\mathrm{al}^{49}$ & 2019 & $14 \mathrm{MpBC}$ & SP263 & $>1+$ intensity in $>1 \%$ immune cells & $50 \%$ immune cells \\
\hline Lien et $\mathrm{al}^{63}$ & 2020 & $82 \mathrm{MpBC}$ & $\mathrm{SPI} 42$ & $\%$ tumor cells; immune cells as $\%$ of tumor area & $17 \%$ tum; $48 \%$ immune cell \\
\hline Kalaw et a ${ }^{64}$ & 2020 & $125 \mathrm{MpBC}$ & EIL3N & $\begin{array}{l}\geq 5 \% \text { tumor/immune cells displaying cyto. or } \\
\text { memb. staining }\end{array}$ & $73 \%$ tum, $69 \%$ stromal TILS \\
\hline Chao et $\mathrm{al}^{65}$ & 2020 & $60 \mathrm{MpBC}$ & EIL3N & $\geq 1 \%$ memb. or cyto. Staining & $50 \%$ tum, $60 \%$ TILs \\
\hline
\end{tabular}

Abbreviations: $B C$, breast cancer; ER, estrogen receptor; IBC-NST, invasive breast cancer-no special type; MpBC, metaplastic breast cancer; NACT, neo-adjuvant chemotherapy; PR, progesterone receptor; TILs, tumour infiltrating lymphocytes; TNBC, triple-negative breast cancer; Cyto, cytoplasmic; memb., membraneous; tum, tumour. 
supports further investigation. It is hoped that trials such as the Morpheus-TNBC Phase 1/1b umbrella trial (Table 2, NCT03424005), will provide insights to further our understanding of the biomarkers and patient indicators for a range of immunotherapeutic interventions.

\section{Summary}

The morphologically diverse metaplastic breast cancers account for significant global morbidity and mortality, in spite of their relatively rare frequency, due to their aggressive clinical course. As more molecular pathology data emerges on the genomic underpinnings of this intriguing tumor type, we are increasingly better placed to consider $\mathrm{MpBC}$ for targeted therapies and immunotherapies.

\section{Acknowledgments}

We apologize to those authors' whose work we could not include due to space restrictions.

\section{Disclosure}

The authors report no conflicts of interest in this work.

\section{References}

1. Board WCoTE. Breast Tumours. Lyon, France: Interantional Agency for Research on Cancer; 2019.

2. Reis-Filho J, Gobbi H, McCart Reed A, et al. Metaplastic Breast Cancer. Board WCoTE, editor. Breast Cancer. Lyon, France: International Agency for Research on Cancer. 2019. 135-138.

3. Schroeder MC, Rastogi P, Geyer CE, Miller LD, Thomas A. Early and Locally Advanced Metaplastic Breast Cancer: presentation and Survival by Receptor Status in Surveillance, Epidemiology, and End Results (SEER) 2010-2014. Oncologist. 2018;23(4):481-488.

4. Lei $\mathrm{T}, \mathrm{Pu} \mathrm{T}$, Wei $\mathrm{B}$, et al. Clinicopathologic characteristics of HER2-positive metaplastic squamous cell carcinoma of the breast. J Clin Pathol. 2020.

5. Hennessy BT, Gonzalez-Angulo AM, Stemke-Hale K, et al. Characterization of a naturally occurring breast cancer subset enriched in epithelial-to-mesenchymal transition and stem cell characteristics. Cancer Res. 2009;69(10):4116-4124.

6. Taube JH, Herschkowitz JI, Komurov K, et al. Core epithelial-tomesenchymal transition interactome gene-expression signature is associated with claudin-low and metaplastic breast cancer subtypes. Proc Natl Acad Sci U S A. 2010;107(35):15449-15454.

7. Fougner C, Bergholtz H, Norum JH, Sorlie T. Re-definition of claudin-low as a breast cancer phenotype. Nat Commun. 2020;11 (1):1787.

8. Ai D, Yao J, Yang F, et al. TRPS1: a highly sensitive and specific marker for breast carcinoma, especially for triple-negative breast cancer. Mod Pathol. 2020.

9. Rakha EA, Coimbra ND, Hodi Z, Juneinah E, Ellis IO, Lee AH. Immunoprofile of metaplastic carcinomas of the breast. Histopathology. 2017;70(6):975-985.

10. Rakha E, Quinn CM, Pia Foschini M, et al. Metaplastic carcinomas of the breast without evidence of epithelial differentiation: a diagnostic approach for management. Histopathology. 2020. doi:10. 1111/his. 14290
11. McCart Reed AE, Kalaw E, Nones K, et al. Phenotypic and molecular dissection of Metaplastic Breast Cancer and the prognostic implications. J Pathol. 2019;247(2):214-227. doi:10.1002/path.5184

12. Rayson D, Adjei AA, Suman VJ, Wold LE, Ingle JN. Metaplastic breast cancer: prognosis and response to systemic therapy. Ann Oncol. 1999;10(4):413-419. doi:10.1023/A:1008329910362

13. Tzanninis I-G, Kotteas EA, Ntanasis-Stathopoulos I, Kontogianni P, Fotopoulos G. Management and Outcomes in Metaplastic Breast Cancer. Clin Breast Cancer. 2016;16(6):437-443. doi:10.1016/j.clbc. 2016.06.002

14. Sulaiman A, McGarry S, Han X, Liu S, Wang L. CSCs in Breast Cancer-One Size Does Not Fit All: therapeutic Advances in Targeting Heterogeneous Epithelial and Mesenchymal CSCs. Cancers. 2019;11(8):8. doi:10.3390/cancers11081128

15. Zhang Y, Toy KA, Kleer CG. Metaplastic breast carcinomas are enriched in markers of tumor-initiating cells and epithelial to mesenchymal transition. Mod Pathol. 2012;25(2):178-184. doi:10.10 38/modpathol.2011.167

16. Gerhard R, Ricardo S, Albergaria A, et al. Immunohistochemical features of claudin-low intrinsic subtype in metaplastic breast carcinomas. Breast. 2012;21(3):354-360. doi:10.1016/j.breast.2012.03.001

17. May CD, Sphyris N, Evans KW, Werden SJ, Guo W, Mani SA. Epithelial-mesenchymal transition and cancer stem cells: a dangerously dynamic duo in breast cancer progression. Breast Cancer Res. 2011;13(1):202. doi:10.1186/bcr2789

18. Nunes T, Hamdan D, Leboeuf C, et al. Targeting Cancer Stem Cells to Overcome Chemoresistance. Int J Mol Sci. 2018;19(12):12. doi:10.3390/ijms19124036

19. Yuan H, Chen J, Liu Y, et al. Association of PIK3CA mutation status before and after neoadjuvant chemotherapy with response to chemotherapy in women with breast cancer. Clin Cancer Res. 2015;21 (19):4365-4372. doi:10.1158/1078-0432.CCR-14-3354

20. Mosele F, Stefanovska B, Lusque A, et al. Outcome and molecular landscape of patients with PIK3CA-mutated metastatic breast cancer. Ann Oncol. 2020;31(3):377-386. doi:10.1016/j.annonc.2019.11.006

21. Krings G, Chen -Y-Y. Genomic profiling of metaplastic breast carcinomas reveals genetic heterogeneity and relationship to ductal carcinoma. Mod Pathol. 2018;31(11):1661-1674. doi:10.1038/s41379-018-0081-z

22. Gonzalez-Martinez S, Perez-Mies B, Carretero-Barrio I, et al. Molecular features of metaplastic breast carcinoma: an infrequent subtype of triple negative breast carcinoma. Cancers. 2020;12(7):7. doi:10.3390/cancers 12071832

23. Ng CKY, Piscuoglio S, Geyer FC, et al. The landscape of somatic genetic alterations in metaplastic breast carcinomas. Clin Cancer Res. 2017;23(14):3859-3870. doi:10.1158/1078-0432.CCR-16-2857

24. Hayes MJ, Thomas D, Emmons A, Giordano TJ, Kleer CG. Genetic changes of Wnt pathway genes are common events in metaplastic carcinomas of the breast. Clin Cancer Res. 2008;14(13):4038-4044. doi:10.1158/1078-0432.CCR-07-4379

25. Avigdor BE, Beierl K, Gocke CD, et al. Whole-Exome Sequencing of Metaplastic Breast Carcinoma Indicates Monoclonality with Associated ductal carcinoma component. Clin Cancer Res. 2017;23 (16):4875-4884. doi:10.1158/1078-0432.CCR-17-0108

26. Moukarzel L, Ferrando L, Da Cruz Paula A, et al. The genetic landscape of metaplastic breast cancers and uterine carcinosarcomas. Mol Oncol. 2020. doi:10.1002/1878-0261.12813

27. Hennessy BT, Krishnamurthy S, Giordano S, et al. Squamous cell carcinoma of the breast. $J$ Clin Oncol. 2005;23(31):7827-7835. doi:10.1200/JCO.2004.00.9589

28. Abouharb S, Moulder S. Metaplastic breast cancer: clinical overview and molecular aberrations for potential targeted therapy. Curr Oncol Rep. 2015;17(3):431. doi:10.1007/s11912-014-0431-z

29. El Zein D, Hughes M, Kumar S, et al. Metaplastic carcinoma of the breast is more aggressive than triple-negative breast cancer: a study from a single institution and review of literature. Clin Breast Cancer. 2017;17(5):382-391. doi:10.1016/j.clbc.2017.04.009 
30. Han M, Salamat A, Zhu L, et al. Metaplastic breast carcinoma: a clinical-pathologic study of 97 cases with subset analysis of response to neoadjuvant chemotherapy. Mod Pathol. 2019;32(6):807-816.

31. Al-Hilli Z, Choong G, Keeney MG, et al. Metaplastic breast cancer has a poor response to neoadjuvant systemic therapy. Breast Cancer Res Treat. 2019;176(3):709-716.

32. Cimino-Mathews A, Verma S, Figueroa-Magalhaes MC, et al. A clinicopathologic analysis of 45 patients with metaplastic breast carcinoma. Am J Clin Pathol. 2016;145(3):365-372.

33. Hennessy BT, Giordano S, Broglio K, et al. Biphasic metaplastic sarcomatoid carcinoma of the breast. Ann Oncol. 2006;17 (4):605-613.

34. Nagao T, Kinoshita T, Hojo T, Tsuda H, Tamura K, Fujiwara Y. The differences in the histological types of breast cancer and the response to neoadjuvant chemotherapy: the relationship between the outcome and the clinicopathological characteristics. Breast. 2012;21(3):289-295.

35. Aydiner A, Sen F, Tambas M, et al. Metaplastic breast carcinoma versus triple-negative breast cancer: survival and response to treatment. Medicine. 2015;94(52):e2341.

36. Moroney J, Fu S, Moulder S, et al. Phase I study of the antiangiogenic antibody bevacizumab and the mTOR/hypoxia-inducible factor inhibitor temsirolimus combined with liposomal doxorubicin: tolerance and biological activity. Clin Cancer Res. 2012;18(20):5796-5805.

37. Basho RK, Gilcrease M, Murthy RK, et al. Targeting the PI3K/AKT/ mTOR pathway for the treatment of mesenchymal triple-negative breast cancer: evidence from a phase 1 trial of mTOR inhibition in combination with liposomal doxorubicin and bevacizumab. JAMA Oncol. 2017;3(4):509-515.

38. Basho RK, Yam C, Gilcrease M, et al. Comparative Effectiveness of an mTOR-based systemic therapy regimen in advanced, metaplastic and nonmetaplastic triple-negative breast cancer. Oncologist. 2018;23 (11):1300-1309.

39. Yang MH, Chen IC, Lu YS. PI3K inhibitor provides durable response in metastatic metaplastic carcinoma of the breast: a hidden gem in the BELLE-4 study. J Formos Med Assoc. 2019;118(9):1333-1338.

40. Lu YS, Lee KS, Chao TY, et al. A phase ib study of alpelisib or buparlisib combined with tamoxifen plus goserelin in premenopausal women with hr-positive her2-negative advanced breast cancer. Clin Cancer Res. 2020.

41. Coussy F, El Botty R, Lavigne M, et al. Combination of PI3K and MEK inhibitors yields durable remission in PDX models of PIK3CA-mutated metaplastic breast cancers. J Hematol Oncol. 2020;13(1):13.

42. Matutino A, Amaro C, Verma S. CDK4/6 inhibitors in breast cancer: beyond hormone receptor-positive HER2-negative disease. Ther Adv Med Oncol. 2018;10:1758835918818346.

43. Seo T, Noguchi E, Yoshida M, et al. response to dabrafenib and trametinib of a patient with metaplastic breast carcinoma harboring a braf v600e mutation. case rep oncol med. 2020;2020:2518383.

44. Henneman L, van Miltenburg MH, Michalak EM, et al. Selective resistance to the PARP inhibitor olaparib in a mouse model for BRCA1-deficient metaplastic breast cancer. Proc Natl Acad Sci U S A. 2015;112(27):8409-8414.

45. Tray N, Taff J, Adams S. Therapeutic landscape of metaplastic breast cancer. Cancer Treat Rev. 2019;79:101888.

46. Adams S. Dramatic response of metaplastic breast cancer to chemo-immunotherapy. NPJ Breast Cancer. 2017;3:8.

47. Al Sayed AD, Elshenawy MA, Tulbah A, Al-Tweigeri T, Ghebeh H. Complete response of chemo-refractory metastatic metaplastic breast cancer to paclitaxel-immunotherapy combination. Am J Case Rep. 2019;20:1630-1635.
48. Adams S, Othus M, Patel S, et al. Dual anti-CTLA-4 and anti-PD-1 blockade in metaplastic carcinoma of the breast: dart (SWOG S1609, Cohort 36). J Clin Oncol. 2020;38.

49. Afkhami M, Schmolze D, Yost SE, et al. Mutation and immune profiling of metaplastic breast cancer: correlation with survival. PLoS One. 2019;14(11):e0224726.

50. Bataillon G, Fuhrmann L, Girard E, et al. High rate of PIK3CA mutations but no TP53 mutations in low-grade adenosquamous carcinoma of the breast. Histopathology. 2018;73(2):273-283.

51. Beca F, Sebastiao APM, Pareja F, et al. Whole-exome analysis of metaplastic breast carcinomas with extensive osseous differentiation. Histopathology. 2020.

52. Edenfield J, Schammel C, Collins J, Schammel D, Edenfield WJ. Metaplastic breast cancer: molecular typing and identification of potential targeted therapies at a single institution. Clin Breast Cancer. 2017;17(1):e1-e10.

53. Joneja U, Vranic S, Swensen J, et al. Comprehensive profiling of metaplastic breast carcinomas reveals frequent overexpression of programmed death-ligand 1. J Clin Pathol. 2017;70(3):255-259.

54. Ross JS, Badve S, Wang K, et al. Genomic profiling of advanced-stage, metaplastic breast carcinoma by next-generation sequencing reveals frequent, targetable genomic abnormalities and potential new treatment options. Arch Pathol Lab Med. 2015;139(5):642-649.

55. Tray N, Taff J, Singh B, et al. Metaplastic breast cancers: genomic profiling, mutational burden and tumor-infiltrating lymphocytes. Breast. 2018;44:29-32.

56. Vranic S, Stafford P, Palazzo J, et al. Molecular profiling of the metaplastic spindle cell carcinoma of the breast reveals potentially targetable biomarkers. Clin Breast Cancer. 2020;20(4):326-331.

57. Zhai J, Giannini G, Ewalt MD, et al. Molecular characterization of metaplastic breast carcinoma via next-generation sequencing. Hum Pathol. 2019;86:85-92.

58. Dave B, Gonzalez DD, Liu ZB, et al. Role of RPL39 in Metaplastic Breast Cancer. J Natl Cancer Inst. 2017;109:6.

59. Mittendorf EA, Philips AV, Meric-Bernstam F, et al. PD-L1 expression in triple-negative breast cancer. Cancer Immunol Res. 2014;2 (4):361-370.

60. Beckers RK, Selinger CI, Vilain R, et al. Programmed death ligand 1 expression in triple-negative breast cancer is associated with tumour-infiltrating lymphocytes and improved outcome. Histopathology. 2016;69(1):25-34.

61. Dogukan R, Ucak R, Dogukan FM, Tanik C, Citgez B, Kabukcuoglu F. Correlation between the Expression of PD-L1 and Clinicopathological parameters in triple negative breast cancer patients. Eur J Breast Health. 2019;15(4):235-241.

62. Morgan E, Suresh A, Ganju A, et al. Assessment of outcomes and novel immune biomarkers in metaplastic breast cancer: a single institution retrospective study. World J Surg Oncol. 2020;18(1):11.

63. Lien HC, Lee YH, Chen IC, et al. Tumor-infiltrating lymphocyte abundance and programmed death-ligand 1 expression in metaplastic breast carcinoma: implications for distinct immune microenvironments in different metaplastic components. Virchows Arch. 2020;24.

64. Kalaw E, Lim M, Kutasovic JR, et al. Metaplastic breast cancers frequently express immune checkpoint markers FOXP3 and PD-L1. Br J Cancer. 2020.

65. Chao X, Liu L, Sun P, et al. Immune parameters associated with survival in metaplastic breast cancer. Breast Cancer Res. 2020;22(1):92. 


\section{Publish your work in this journal}

Breast Cancer - Targets and Therapy is an international, peer-reviewed open access journal focusing on breast cancer research, identification of therapeutic targets and the optimal use of preventative and integrated treatment interventions to achieve improved outcomes, enhanced survival and quality of life for the cancer patient.
The manuscript management system is completely online and includes a very quick and fair peer-review system, which is all easy to use. Visit http://www.dovepress.com/testimonials.php to read real quotes from published authors. 